\title{
BRCA2: a grown-up cancer susceptibility gene
}

\author{
William D Foulkes ${ }^{1}$ and Kokichi Sugano ${ }^{2}$ \\ 'Departments of Human Genetics, Medicine and Oncology, McGill University, Montreal, Quebec, Canada \\ 2Oncogene Research Unit/Cancer Prevention Unit, Tochigi Cancer Center Research Institute, Tochigi, Japan
}

Correspondence

should be addressed

to W D Foulkes

Email

william.foulkes@mcgill.ca
BRCA2 was discovered by Michael Stratton and coworkers, then at the Institute of Cancer Research, Sutton, United Kingdom in 1995 (Wooster et al. 1995). Thus, BRCA2 is now twenty-one years old this year. In an era when new genes underlying cancer susceptibility have been found at an astonishing pace (Rahman 2014), BRCA2 is a 'fully adult' cancer susceptibility gene: it is one of the most thoroughly investigated human cancer genes. Of course there is still much to know, but it seems a good time to summarize some key themes. The breast is an important target organ within the endocrine system, so in this special issue of Endocrine-Related Cancer, we bring together five reviews, each of which sheds light on different facets of the function and clinical significance of BRCA2.

Starting out from the basics, Orthwein and coworkers (Fradet-Turcotte et al. 2016) lead us, step-by-step, through a detailed appraisal of BRCA2 functions, with a focus on what is unarguably the most important function of BRCA2: DNA repair. It is interesting that nearly all the important, high-risk breast cancer genes have some function relating to DNA repair (Easton et al. 2015), and BRCA2 is perhaps the best example of this. Unlike BRCA1 (Silver \& Livingston 2012), other functions of BRCA2 have been much harder to pin down and Orthwein and coworkers point out that overall, the unifying feature of BRCA2 function is its role in genomic integrity, with an emphasis on the repair of double-strand breaks (DSB) and the limiting of replication stress. Their review starts with a discussion of the key domains within the very large BRCA2 protein, including the BRC domain, consisting of eight motifs of $\sim 35$ amino acids each, critically implicated in binding to RAD51, and then describe how BRCA2 functions relate to these domains. The authors then discuss the more recent work linking BRCA2 to replication stress response, whereby the nucleolytic degradation of stalled replication forks is prevented by the presence of BRCA2.
Notable in this review is the reminder that BRCA2 links DSB to inter-strand crosslink repair, a central function of the Fanconi Anemia family of proteins. Indeed, one of the most striking developments in BRCA2-related research was the discovery by Alan D'Andrea's group that biallelic mutations in BRCA2 lead to a subtype of Fanconi Anemia previously identified as FANCD1 (Howlett et al. 2002).

In the review by Katsuki and Takata (Katsuki \& Takata 2016), the connection between the Fanconi Anemia (FA) pathway and susceptibility to breast and ovarian cancer is discussed in depth. The authors first describe the clinical connections between FA and hereditary breast and ovarian cancer (HBOC) and then cover some of the same terrain reviewed by Orthwein and coworkers, but with a much greater focus on the key function of FA proteins: interstrand crosslink repair (ICL). Katsuki and Takata discuss the FA core complex and the downstream complex, which consist of FANCD2 and FANCI. Again, it is interesting to note that several of the genes in the FA complex are either bona fide breast or ovarian cancer susceptibility genes (BRCA1, BRCA2, PALB2, BRIP1 and RAD51C) or are candidates to play a role in susceptibility (FANCM, SLX4 and XRCC2). Most relevant to BRCA2 is PALB2 (partner and localizer of BRCA2), which is also known as FANCN and is a moderate-to-high-risk breast cancer susceptibility gene (Antoniou et al. 2014).

The work discussed in the first two reviews is put in clinical context by Lord and coworkers (Dhillon et al. 2016), where in a comprehensive review, the authors first consider the clinical aspects of BRCA2, focusing on the cancer risk, and then move on to a review of the types of mutations that affect BRCA2 and the pathological characteristics of the resulting tumors. The authors introduce BRCA2's role in homologous recombination (HR) to set the scene for the major topic of their review: therapeutic exploitation of the lack

This editorial accompanies a thematic review section on 20 Years of BRCA 1 and 2 The Guest Editors for this section were Kokichi Sugano and William Foulkes 
of HR in BRCA2 (and BRCA1)-related tumors by PARP inhibitors. This has turned out to be one of the most exciting developments in all of hereditary cancer and is one of the developments that has turned genetic testing on its head. Initially, when BRCA1 was identified, there was reluctance to offer genetic testing in the clinical setting (Collins 1996), despite some early advocates (Rosenblatt et al. 1996). But now, testing of all tumors for BRCA (and other) mutations, without face-to-face counseling, is being carried out in some centers, directto-consumer germline BRCA gene testing is available and population-based genetic testing is under consideration (Foulkes et al. 2016). Lord and coworkers chart the fascinating journey from the laboratory to early phase I studies that showed a remarkably strong signal with the Kudos compound KU-0058948 that became the AstraZeneca drug, AZD2281 (Fong et al. 2009). The journey continued with the drug later named olaparib in phase II trials and is now licensed as Lynparza (AstraZeneca) for treatment of platinum-sensitive relapsed BRCA-mutated ovarian cancer. This specific indication was based on the results of trial 19, where a significant improvement in progression-free survival was seen in BRCA-mutated relapsed ovarian cancer when olaparib was given as maintenance monotherapy (Ledermann et al. 2014). Despite the lack of effect on overall survival in the original analysis, this is a notable achievement. Lord and coworkers also point to the future with a discussion of trials that include combinations of PARP inhibitors with immune checkpoint inhibitors (e.g. NCT02484404). Unfortunately, resistance often develops, and the authors helpfully remind readers of the challenges ahead.

A common cancer that nearly always presents a therapeutic challenge is pancreas adenocarcinoma. In their in-depth look at BRCA2 and BRCA2, de Mestier and coworkers (de Mestier et al. 2016) review the state of knowledge with regard to the relationship between BRCA2 and pancreas cancer, and how this might be exploited therapeutically. PARP inhibitors, of course, could play a role (Andrei et al. 2015, Kaufman et al. 2015), but it is not known whether this class of drug will be as effective in treatment of BRCA-related pancreas cancer, compared with BRCA-related ovarian cancer, where the effect is most pronounced thus far. The authors review the genetics of hereditary pancreas cancer and then discuss in greater detail the relationship between BRCA2 and pancreas cancer. This is appropriate because BRCA2 is still the most important pancreas gene, many years after the association was made (Goggins et al. 1996, Ozcelik et al. 1997). The review then discusses a broad range of management issues for BRCA2-related pancreas cancer, including some of the newer therapies discussed previously.

The most clinically relevant and most deeply investigated aspect of BRCA2 is its association with risk for breast cancer. In a very thorough review that concludes this special issue, Milne and Antoniou (Milne \& Antoniou 2016) bring us right up to date with a question that troubles health professionals and patients in almost every clinic: what is my risk for cancer? We know the risk for breast, ovarian and other cancers that are related to BRCA2 mutations vary substantially, even within families, yet up until recently, we had nothing better to say than 'your risk is somewhere between 30 and $80 \%$ '. Because of the power of genetics, international collaborations, such as CIMBA, co-led by one of the authors, have collected data on tens of thousands of BRCA gene carriers in a global effort to identify the critical modifiers that will be needed to be incorporated into risk assessment programs, such as BOADICEA (Antoniou et al. 2004). As we move forward with near-populationbased testing (http://www.genomicsengland.co.uk), these estimates of risk will need to be made much more precise if we are not to over-treat those at lower risk and under-treat those at higher risk. Milne and Antoniou review the considerable amount of data on genetic modifiers of BRCA2 and point out that, thus far, our understanding of the effect of varying lifestyles and hormone levels are unfortunately much less well understood. Importantly, the authors provide a pathway to how knowledge of these modifying factors could be incorporated into clinical practice.

These five reviews, from basic to applied research, show how discovery of a single gene can have widespread, population-based impact across all aspects of cancer management. From discovery to age 21, BRCA2 has gradually revealed itself as one of the most important cancer genes ever discovered. We hope you enjoy this series of articles.

\section{Declaration of interest}

The authors declare that there is no conflict of interest that could be perceived as prejudicing the impartiality of this editorial.

\section{Funding}

This editorial did not receive any specific grant from any funding agency in the public, commercial or not-for-profit sector. 


\section{References}

Andrei AZ, Hall A, Smith AL, Bascunana C, Malina A, Connor A, AltinelOmeroglu G, Huang S, Pelletier J, Huntsman D, et al. 2015 Increased in vitro and in vivo sensitivity of BRCA2-associated pancreatic cancer to the poly(ADP-ribose) polymerase-1/2 inhibitor BMN 673 . Cancer Letters 364 8-16. (doi:10.1016/j.canlet.2015.04.003)

Antoniou AC, Casadei S, Heikkinen T, Barrowdale D, Pylkas K, Roberts J, Lee A, Subramanian D, De Leeneer K, Fostira F, et al. 2014 Breastcancer risk in families with mutations in PALB2. New England Journal of Medicine 371 497-506.

Antoniou AC, Pharoah PP, Smith P \& Easton DF 2004 The BOADICEA model of genetic susceptibility to breast and ovarian cancer. British Journal of Cancer 91 1580-1590.

Collins FS 1996 BRCA1 - lots of mutations, lots of dilemmas. New England Journal of Medicine 334 186-188. (doi:10.1056/ nejm199601183340311)

Dhillon KK, Bajrami I, Taniguchi T \& Lord C 2016 Synthetic lethality: the road to novel therapies for breast cancer. Endocrine-Related Cancer 23 T39-T55. (doi:10.1530/ERC-16-0228)

Easton DF, Pharoah PD, Antoniou AC, Tischkowitz M, Tavtigian SV, Nathanson KL, Devilee P, Meindl A, Couch FJ, Southey M, et al. 2015 Gene-panel sequencing and the prediction of breast-cancer risk. New England Journal of Medicine 372 2243-2257. (doi:10.1056/ nejmsr1501341)

Fong PC, Boss DS, Yap TA, Tutt A, Wu P, Mergui-Roelvink M, Mortimer P, Swaisland H, Lau A, O'connor MJ, et al. 2009 Inhibition of poly(ADP-ribose) polymerase in tumors from BRCA mutation carriers. New England Journal of Medicine 361 123-134. (doi:10.1056/ nejmoa0900212)

Foulkes WD, Knoppers BM \& Turnbull C 2016 Population genetic testing for cancer susceptibility: founder mutations to genomes. Nature Reviews Clinical Oncology 13 41-54. (doi:10.1038/nrclinonc.2015.173)

Fradet-Turcotte A, Sitz J, Grapton D \& Orthwein A 2016 BRCA2 functions: from DNA repair to replication fork stabilization. Endocrine-Related Cancer 23 T1-T17. (doi:10.1530/ERC-16-0297)

Goggins M, Schutte M, Lu J, Moskaluk CA, Weinstein CL, Petersen GM, Yeo CJ, Jackson CE, Lynch HT, Hruban RH, et al. 1996 Germline BRCA2 gene mutations in patients with apparently sporadic pancreatic carcinomas. Cancer Research 56 5360-5364.
Howlett NG, Taniguchi T, Olson S, Cox B, Waisfisz Q, Die-Smulders C, Persky N, Grompe M, Joenje H, Pals G, et al. 2002 Biallelic inactivation of BRCA2 in Fanconi anemia. Science 297 606-609. (doi:10.1126/science.1073834)

Katsuki Y \& Takata M 2016 Defects in HR repair behind the human diseases: FA and HBOC. Endocrine-Related Cancer 23 T19-T37. (doi:10.1530/ERC-16-0221)

Kaufman B, Shapira-Frommer R, Schmutzler RK, Audeh MW, Friedlander M, Balmana J, Mitchell G, Fried G, Stemmer SM, Hubert A, et al. 2015 Olaparib monotherapy in patients with advanced cancer and a germline BRCA1/2 mutation. Journal of Clinical Oncology 33 244-250. (doi:10.1200/jco.2014.56.2728)

Ledermann J, Harter P, Gourley C, Friedlander M, Vergote I, Rustin G, Scott CL, Meier W, Shapira-Frommer R, Safra T, et al. 2014 Olaparib maintenance therapy in patients with platinum-sensitive relapsed serous ovarian cancer: a preplanned retrospective analysis of outcomes by BRCA status in a randomised phase 2 trial. Lancet Oncology 15 852-861. (doi:10.1016/s1470-2045(14)70228-1)

de Mestier L, Danset J-B, Neuzillet C, Rebours V, Cros J, Soufir N \& Hammel P 2016 Pancreatic ductal adenocarcinoma in BRCA2 mutation carriers. Endocrine-Related Cancer 23 T57-T67. (doi:10.1530/ERC-16-0269)

Milne RL \& Antoniou A 2016 Modifiers of breast and ovarian cancer risks for BRCA1 and BRCA2 mutation carriers. Endocrine-Related Cancer 23 T69-T84. (doi:10.1530/ERC-16-0277)

Ozcelik H, Schmocker B, Di Nicola N, Shi XH, Langer B, Moore M, Taylor BR, Narod SA, Darlington G, Andrulis IL, et al. 1997 Germline BRCA2 6174delT mutations in Ashkenazi Jewish pancreatic cancer patients. Nature Genetics 16 17-18. (doi:10.1038/ng0597-17)

Rahman N 2014 Realizing the promise of cancer predisposition genes. Nature 505 302-308. (doi:10.1038/nature12981)

Rosenblatt DS, Foulkes WD \& Narod SA 1996 Genetic screening for breast cancer. New England Journal of Medicine 334 1200-1201.

Silver DP \& Livingston DM 2012 Mechanisms of BRCA1 tumor suppression. Cancer Discovery 2 679-684. (doi:10.1158/2159-8290. CD-12-0221)

Wooster R, Bignell G, Lancaster J, Swift S, Seal S, Mangion J, Collins N, Gregory S, Gumbs C, Micklem G, et al. 1995 Identification of the breast cancer susceptibility gene BRCA2. Nature 378 789-792. (doi:10.1038/378789a0)

Received in final form 12 August 2016

Accepted 12 August 2016
(C) 2016 Society for Endocrinology Printed in Great Britain
Published by Bioscientifica Ltd 